\title{
Stable Li metal anode by crystallographically oriented plating through in-situ surface doping
}

\author{
Yangyang Liu ${ }^{1 \dagger}$, Shizhao Xiong ${ }^{2 \dagger}$, Junkai Deng ${ }^{1}$, Xingxing Jiao ${ }^{1}$, Baorui Song ${ }^{1}$, \\ Aleksandar Matic ${ }^{2}$ and Jiangxuan Song ${ }^{1 *}$
}

\begin{abstract}
Lithium (Li) metal is regarded as the holy grail anode material for high-energy-density batteries owing to its ultrahigh theoretical specific capacity. However, its practical application is severely hindered by the high reactivity of metallic Li against the commonly used electrolytes and uncontrolled growth of mossy/dendritic Li. Different from widely-used approaches of optimization of the electrolyte and/ or interfacial engineering, here, we report a strategy of in-situ cerium (Ce) doping of $\mathrm{Li}$ metal to promote the preferential plating along the [200] direction and remarkably decreased surface energy of metallic Li. The in-situ Ce-doped Li shows a significantly reduced reactivity towards a standard electrolyte and, uniform and dendrite-free morphology after plating/ stripping, as demonstrated by spectroscopic, morphological and electrochemical characterizations. In symmetric half cells, the in-situ Ce-doped Li shows a low corrosion current density against the electrolyte and drastically improved cycling even at a lean electrolyte condition. Furthermore, we show that the stable $\mathrm{Li} \mid \mathrm{LiCoO}_{2}$ full cells with improved coulombic efficiency and cycle life are also achieved using the Ce-doped Li metal anode. This work provides an inspiring approach to bring $\mathrm{Li}$ metal towards practical application in high energy-density batteries.
\end{abstract}

Keywords: Li metal anode, crystallographically oriented plating, in-situ cerium doping, low surface energy

\section{INTRODUCTION}

Nowadays, there is a growing need to develop high-energy-density batteries for power applications, such as portable electronic devices, and electric vehicles [1-3]. Decades after the commercialization, conventional lithium (Li) ion batteries (LIBs) have reached a performance close to their theoretical limitation in terms of gravimetric/volumetric energy densities. Li metal batteries using metallic $\mathrm{Li}$ as anodes have the potential to reach an energy density beyond the limitation of LIBs as a result of the ultrahigh theoretical specific capacity (3860 $\mathrm{mA} \mathrm{h} \mathrm{g}^{-1}$ ) of metallic $\mathrm{Li}$, the low electrochemical reduction potential $(-3.04 \mathrm{~V}$ vs. standard hydrogen electrode) and the low density $\left(0.534 \mathrm{~g} \mathrm{~cm}^{-3}\right)$ [4-6]. However, Li metal batteries typically show low coulombic efficiency (CE) and thus poor cycling life due to the high reactivity of Li metal with the commonly used liquid electrolytes and the formation of mossy and dendritic $\mathrm{Li}$, which hinder their realization in practice $[7,8]$. The high reactivity readily promotes aggressive formation of a solid electrolyte interphase (SEI) on Li metal [8-10]. The asformed SEI alters the local electric field and the Li-ion flux during plating/stripping, which stimulates the growth of a mossy/dendritic Li. The SEI has poor passivation and insufficient mechanical strength to suppress the growth of mossy/dendritic Li and, consequently, the SEI breaks down with further exposure of $\mathrm{Li}$ and reaction with electrolyte. This repeated process leads to accumulation of isolated mossy/dendritic Li covered by a thick SEI and continuous consumption of electrolyte, resulting in failure of the cell [11-15].

Many approaches have been taken to address the above-mentioned issues in order to improve Li plating/ stripping [16-18]. Optimization of the electrolyte is a widely used approach to improve SEI formation and facilitate uniform deposition of $\mathrm{Li}$ metal [19], including using new electrolytes [20-23], highly concentrated electrolytes [24-27] and/or new additives [28-30]. Another efficient method is the modification of the interface between Li metal and electrolyte by applying an artificial layer of materials such as organosulfide, polyvinyl alco-

\footnotetext{
${ }^{1}$ State Key Laboratory for Mechanical Behavior of Materials, Xi'an Jiaotong University, Xi'an 710049, China

${ }^{2}$ Department of Physics, Chalmers University of Technology, SE 412 96, Göteborg, Sweden

${ }^{\dagger}$ These authors contributed equally to this work.

* Corresponding author (email: songjx@xjtu.edu.cn)
} 
hol, highly elastic polyrotaxane, $\mathrm{LiF} / \mathrm{h}-\mathrm{BN}$ or $\mathrm{Li}_{2} \mathrm{~S}_{6} / \mathrm{P}_{2} \mathrm{~S}_{5}$ [31-38].

Intrinsically, $\mathrm{Li}$ is a kind of alkali metal with a body centered cubic (BCC) crystal structure [39-41]. The plating of metallic $\mathrm{Li}$ is electrochemical nucleation and growth of Li crystals that is strongly related to the crystal structure and orientation as well as surface energy of Li metal substrate, along with the electrolyte and interface properties as mentioned above [42-47]. Following the thought, herein, we developed an approach of an in-situ elemental doping to Li metal and surprisingly found $\mathrm{Li}$ metal can plate/strip with a preferred crystalline orientation with low surface energy and thus result in a low reactivity against the electrolyte. By this in-situ elemental doping into Li metal, we demonstrated Ce doping at the top surface of Li metal facilitated the crystallographically oriented growth of Li metal along the [200] direction with uniform Li plating morphology verified by X-ray diffraction (XRD) and scanning electron microscopy (SEM). Density functional theory (DFT) calculations further confirmed that Ce-doped (200) crystal facets had the lowest surface energy, even lower than any low-surfaceenergy facets of the native Li crystal. Benefiting from lowsurface-energy facets exposed to the electrolyte, the decrease in reactivity of Li metal towards the electrolyte was verified by the observation of a low corrosion current density. As a result, Li plating/stripping showed an improved $\mathrm{CE}$ in $\mathrm{Li} \mid \mathrm{Li}$ symmetric cells, even at lean electrolyte condition $(8.6 \mu \mathrm{L}$ electrolyte per $1 \mathrm{~mA} \mathrm{~h} \mathrm{Li} \mathrm{metal).}$ Furthermore, $\mathrm{Li} \mid \mathrm{LiCoO}_{2}$ full cells utilizing the in-situ Cedoped Li metal demonstrated a superior cycling stability. The crystal-orientation controlled growth of $\mathrm{Li}$ metal provides a novel pathway to address the challenge of $\mathrm{Li}$ metal anodes and to improve the performances of highenergy-density Li metal batteries.

\section{EXPERIMENTAL SECTION}

\section{Pre-treatment of lithium metal anode}

Firstly, $500 \mathrm{mg}$ of cerium fluoride $\left(\mathrm{CeF}_{3}\right)$ and $200 \mathrm{mg}$ of polyvinylidene fluoride (PVDF) were dispersed in $50 \mathrm{~g}$ of dimethyl sulfoxide (DMSO). The mass percent of PVDF for total solid materials is $28.6 \%$. The mixture was magnetically stirred overnight. Subsequently, the slurry was coated on a $\mathrm{Li}$ foil in an argon-filled glove box $\left(\mathrm{H}_{2} \mathrm{O}\right.$ $\left.<0.1 \mathrm{ppm}, \mathrm{O}_{2}<0.1 \mathrm{ppm}\right)$. The $\mathrm{Li}$ foil with the $\mathrm{CeF}_{3}$ coating was transferred into a vacuum oven and dried at $60^{\circ} \mathrm{C}$ for $12 \mathrm{~h}$. Before use, the modified Li foil was punched into electrodes with a diameter of $15.0 \mathrm{~mm}$. Lithium metal coated by lithium fluoride $(\mathrm{LiF})$ was prepared with the same procedure and used as the control sample.

\section{Preparation of $\mathrm{LiCoO}_{2}$ cathode}

The slurry of lithium cobalt oxide $\left(\mathrm{LiCoO}_{2}\right)$ for the cathode was made by mixing $\mathrm{LiCoO}_{2}$, Super-P and PVDF in a weight ratio of $8: 1: 1$. The mixture was magnetically stirred for $1 \mathrm{~h}$ to make uniform slurry and the obtained slurry was cast onto the aluminium (Al) foil and then dried at $100^{\circ} \mathrm{C}$ in vacuum overnight. The cathode was punched into electrodes with a diameter of $12.0 \mathrm{~mm}$. The loading of active materials is approximately $8.0 \mathrm{mg} \mathrm{cm}^{-2}$.

\section{Electrochemical measurements}

All electrochemical measurements were carried out in standard CR2032 coin-type cells assembled in an argonfilled glove box $\left(\mathrm{H}_{2} \mathrm{O}<0.1 \mathrm{ppm}, \mathrm{O}_{2}<0.1 \mathrm{ppm}\right)$. The electrolyte was $1 \mathrm{~mol} \mathrm{~L}^{-1}$ lithium hexafluorophosphate $\left(\mathrm{LiPF}_{6}\right)$ in ethylene carbonate/diethyl carbonate $=1: 1(\mathrm{EC} /$ $\mathrm{DEC}=1: 1)$. To assemble the symmetrical cell, Li foil, separator (Celgard 2400) and Li disk (15 mm diameter) were placed in a sandwich structure with $40 \mu \mathrm{L}$ (sufficient) and $15 \mu \mathrm{L}$ (lean) of electrolyte, respectively. The capacity for Li plating-stripping was set as $1.0 \mathrm{~mA} \mathrm{~h} \mathrm{~cm}$. The $\mathrm{CE}$ was investigated in $\mathrm{Li} \mid \mathrm{Cu}$ half-cells, using $\mathrm{Ce}$ doped $\mathrm{Li}$ metal as anode, $\mathrm{Cu}$ as cathode and $1 \mathrm{~mol} \mathrm{~L}^{-1}$ $\mathrm{LiPF}_{6}$ in EC/DEC=1:1 as electrolyte. The Li|Cu half-cells were operated at a current density of $1.0 \mathrm{~mA} \mathrm{~cm}^{-2}$ and a capacity density of $2.0 \mathrm{~mA} \mathrm{~h} \mathrm{~cm}^{-2}$. $\mathrm{Li} \mid \mathrm{LiCoO}_{2}$ full cells were assembled in a standard CR2032 type coin cell with $20 \mu \mathrm{L}$ electrolyte. The voltage range was limited to $3.0-$ $4.2 \mathrm{~V}$ in each cycle. The corrosion test was conducted at a $\mathrm{CHI}$ electrochemical station with a voltage range from -0.15 to $0.15 \mathrm{~V}$ at a scanning rate of $1.0 \mathrm{mV} \mathrm{s}^{-1}$. Electrochemical impedance spectroscopy (EIS) was carried out on a Solartron analytical instrument within a frequency range from $0.1 \mathrm{~Hz}$ to $1 \mathrm{MHz}$ at room temperature.

\section{Characterization}

An XRD-6100 powder diffractometer was used to record $\mathrm{XRD}$ patterns with $\mathrm{Cu} \mathrm{Ka}$ radiation, in the range from $20^{\circ}$ to $80^{\circ}$ with a scanning speed of $5^{\circ} \mathrm{min}^{-1}$. The sample was covered by Kapton membrane to avoid air exposure. The ESCALAB Xi+ was used for X-ray photoelectron spectroscopy (XPS) with monochromatic Al Ka radiation under a vacuum of $2 \times 10^{-6} \mathrm{~Pa}$. The morphologies of the electrodes after cycling were characterized by a Gemini SEM 500 field-emission scanning electron microscope (FESEM).

\section{Calculation of surface energy with DFT}

The Vienna Ab-initio Simulation Package (VASP) was 
used to conduct DFT calculation with the projector augmented wave method [48]. The generalized gradient approximation (GGA) with the Perdew-Burke-Ernzerhof (PBE) functional was adopted [49]. The kinetic energy cutoff for wavefunction expansion was set to $520 \mathrm{eV}$. Monkhorst-Pack k-point grids of $19 \times 19 \times 19,9 \times 9 \times 1$ and $3 \times 3 \times 1$ were used for bulk BCC Li, pure Li slabs and Ce-doped Li supercell slabs, respectively. (200), (211) and (110) Li slabs were expanded to $2 \times 2,4 \times 2$ and $4 \times 2$ supercell in order to keep the same total number of atoms in each slabs, and then only one Ce was doped into one surface leading to $1 / 95 \mathrm{Li} / \mathrm{Ce}$ ratio in every slabs. Atomic positions and lattice constants were fully relaxed in bulk $\mathrm{Li}$. The relaxed lattice constant was used in two middle atomic layers for slab calculations. In addition, the two layers on surfaces of slabs were relaxed to get surface effects. The periodic boundary condition was applied along the $x$ and $y$ axes and vacuum space was applied along the $z$ axis at least $20 \AA$ to safely avoid artificial interaction between the slabs and periodic images. All relaxations were terminated until the differences of energy and forces were less than $10^{-5} \mathrm{eV}$ and $0.01 \mathrm{eV} \AA^{-1}$, respectively.

\section{Calculation of texture index and total surface energy}

Quantitative analyses of XRD peaks can be described by texture index (TI), obtained with the following equation:

$\mathrm{TI}=\frac{I_{h k l} / I_{h k l}^{0}}{\frac{1}{n} \sum\left(I_{h k l} / I_{h k l}^{0}\right)}$,

where $I_{h k l}$ and $I_{h k l}^{0}$ are the integral intensities of the $(h k l)$ diffraction peaks for the various electrodes and standard lithium (JCPDS 15-0401), respectively, and $n$ is the number of diffraction peaks in the XRD patterns [39]. The total surface energy of bare Li and Ce-doped Li can be calculated with surface energy of each crystal plane and TI. It is described by the following equation:

$\bar{E}_{\text {total }}=\sum \frac{\mathrm{TI}_{h k l} / \bar{E}_{h k l}}{\sum \mathrm{TI}_{h k l}}$

where $\mathrm{TI}_{h k l}$ is the texture index of the $(h k l)$ diffraction peak and $E_{h k l}$ is the surface energy of $(h k l)$ crystal plane.

\section{RESULTS AND DISCUSSION}

The in-situ Ce doping into $\mathrm{Li}$ was accomplished via coating a composite layer of $\mathrm{CeF}_{3}$ nanoparticles and a polymer on fresh Li metal followed by in-situ chemical reduction by $\mathrm{Li}$. To form the composite layer, dried $\mathrm{CeF}_{3}$ nanoparticles and PVDF were dispersed in DMSO and stirred to form a slurry, followed by casting on a fresh $\mathrm{Li}$ foil (Fig. 1a). The SEM images (Fig. 1b, c) clearly show that the surface of the Li-metal foil is covered by a composite layer containing agglomerated nanoparticles with a mean size of $20 \mathrm{~nm}$ (Fig. S1). The thickness of this layer is optimized to be about $1 \mu \mathrm{m}$ (Fig. 1c).

Because of the lower reduction potential of $\mathrm{Li}$ compared with $\mathrm{Ce}\left(\varphi_{\mathrm{Li}^{+} / \mathrm{Li}}^{0}=-3.04 \mathrm{~V}, \varphi_{\mathrm{Ce}^{3+} / \mathrm{Ce}}^{0}=-2.336 \mathrm{~V}\right)$, $\mathrm{CeF}_{3}$ nanoparticles can be chemically reduced by $\mathrm{Li}$ to form $\mathrm{Ce}(0)$ species (e.g., Ce metal or $\mathrm{LiCe}_{x}$ ) spontaneously after coating the Li metal surface with $\mathrm{CeF}_{3}$. XPS was carried out to verify the chemical reaction between the $\mathrm{CeF}_{3}$-containing layer and $\mathrm{Li}$. In the XPS spectra of the $\mathrm{CeF}_{3}$-coated $\mathrm{Li}$, the peaks located at 883.9 and $55.7 \mathrm{eV}$ are attributed to metallic Ce (Fig. 2a) and $\mathrm{Li}^{+}$in $\mathrm{LiF}$ (Fig. 2b), respectively [50]. These results confirm the successful reduction of $\mathrm{CeF}_{3}$, generating $\mathrm{Ce}$ species and $\mathrm{LiF}$. The Ce species and LiF are also observed on the surface of cycled Li (Fig. S2a, b), showing the stability of this surface modification.

XRD experiments were performed to track the evolution of the crystal structure of cycled Li metal anodes that were retrieved from symmetric $\mathrm{Li} \mid \mathrm{Li}$ cells. The XRD patterns of the bare $\mathrm{Li}$ and $\mathrm{Ce}$-doped $\mathrm{Li}$ are shown in Fig. $2 a$ and $b$, respectively. In general, texture index (TI) is defined for quantification of the typical texture orientations in crystals, and the facets with TI value greaterthan-1 are regarded as the preferred orientation (see details in EXPERIMENTAL SECTION) [39]. As shown in Fig. 2c, Li metal exhibits three reflection peaks related to the (110), (200), and (211) planes. Among these, the (110) plane shows the highest TI of 1.26 for bare Li metal (Table S1), indicating the (110) direction is the preferred orientation of plated Li upon cycling [39]. In contrast, the (200) planes in the Ce-doped Li metal, show the highest TI value (2.34 after 10 cycles) and are thus the preferred growth orientation (Fig. 2d). Noticeably, a reflection peak at a $2 \theta$ of $32.4^{\circ}$ is observed and attributed to $\mathrm{LiCe}_{3}$ [51]. We suggest that the interfacial region of Ce-doped $\mathrm{Li}$ exists due to the similar ionic radius of $\mathrm{Ce}$ with $\mathrm{Na}$ and $\mathrm{K}$ which can readily form an alloy with $\mathrm{Li}$ and thus fundamentally change the surface energy of Li metal and the growth orientation. To verify this hypothesis and illustrate the doping effect of Ce, DFT calculations were performed to calculate the surface energy of different crystal facets [52]. The total energy, surface area and surface energy of all slab structures are summarized in Table S2. In bare Li, the surface energy difference between the three surfaces is $E_{\mathrm{Li}}(110)<E_{\mathrm{Li}}(211)<E_{\mathrm{Li}}(200)$, which means that (110) is the most stable surface and 

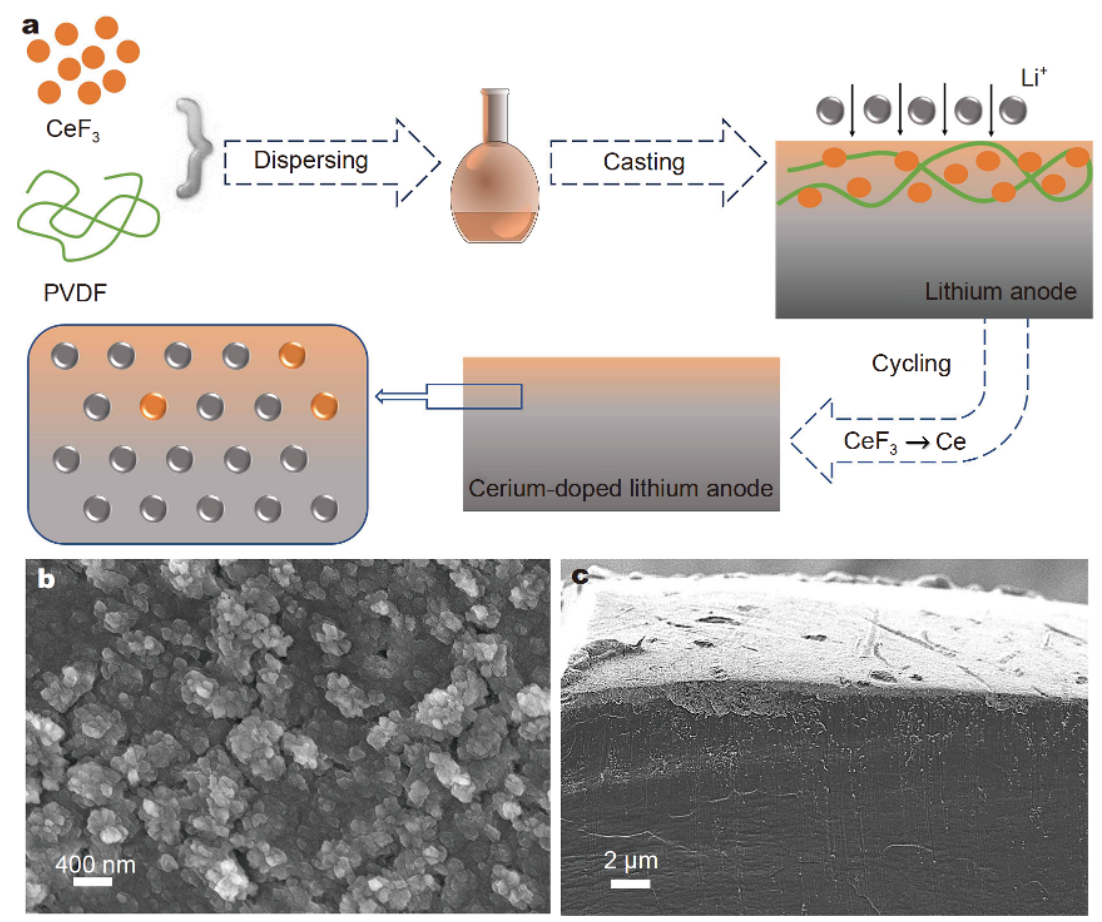

Figure 1 Schematic illustration of the fabrication process of the in-situ Ce-doped Li metal anode (a). Top-view (b) and cross-sectional (c) SEM images of the Ce-doped Li metal.

(200) is a high-activity surface. Interestingly, the Ce doping changes the surface energy and the energy relationship is changed to $\bar{E}_{\mathrm{Ce}-\mathrm{Li}}(200)<\bar{E}_{\mathrm{Ce}-\mathrm{Li}}(110)<$ $\bar{E}_{\mathrm{Ce}-\mathrm{Li}}(211)$. This result indicates that the Ce doping grants (200) plane to have the lowest surface energy (Fig. 2f). Collectively, the total weighted surface energy of the crystalline Li metal can be further calculated using the DFT calculated surface energy and the TI values obtained from XRD patterns (Table S3). It is found that the Ce doping prominently lowers the total weighted surface energy of Li metal upon cycling. This indicates that the Ce doping intrinsically lowers the surface energy of crystal metallic Li and potentially lowers the reactivity of Li metal against the electrolyte [53-55].

Another advantage of the process used for Ce doping is the spontaneous generation of LiF by the in-situ chemical reduction of $\mathrm{CeF}_{3}$ with $\mathrm{Li}$ metal. The protective effects of $\mathrm{LiF}$ to improve the SEI and cycling of Li metal are well known [56-60]. Following previous reports, a control sample of LiF-coated Li metal (see details in EXPERIMENTAL SECTION) was fabricated, which showed improved cycle life compared with bare Li metal (Fig. S3). However, the preferred plating orientation was not observed in the case of the LiF-coated $\mathrm{Li}$ metal (Fig. S4). This demonstrates that the preferred oriented growth of Li metal originates from the Ce doping rather than $\mathrm{LiF}$ coating. In our approach, the $\mathrm{LiF}$ particles are spontaneously produced by the interfacial chemical reduction of $\mathrm{CeF}_{3}$ and are thus in intimate contact with the Li metal. With combined effects from Ce doping and intimate $\mathrm{LiF}$ protection, the in-situ Ce-doped $\mathrm{Li}$ metal possesses low surface reactivity and is expected to show improved electrochemical performance.

More evidence of the effect of lowering the reactivity via Ce doping can be obtained from potentiodynamic polarization experiments (Fig. 3) [53]. The potentiodynamic polarization curves show that the Ce-doped $\mathrm{Li}$ exhibits a lower corrosion current density during the whole cycling life, which suggests that the Ce-doped $\mathrm{Li}$ exhibits a higher corrosion resistance towards the liquid electrolyte. In addition, EIS was conducted to investigate the stabilization of the interface obtained on the Cedoped Li (Fig. S5a, b). A low and stable impedance demonstrates less accumulation of by-products on the Cedoped Li metal, resulting from the supressed side reactions. All above evidences confirm that Ce doping can stabilize the metallic $\mathrm{Li}$ metal and lower the reactivity towards electrolyte. Moreover, a $\mathrm{Li} \mid \mathrm{Cu}$ half-cell was assembled and operated at a current density of $0.5 \mathrm{~mA} \mathrm{~cm}{ }^{-2}$ and a capacity density of $1.0 \mathrm{~mA} \mathrm{~h} \mathrm{~cm}^{-2}$ to evaluate the 

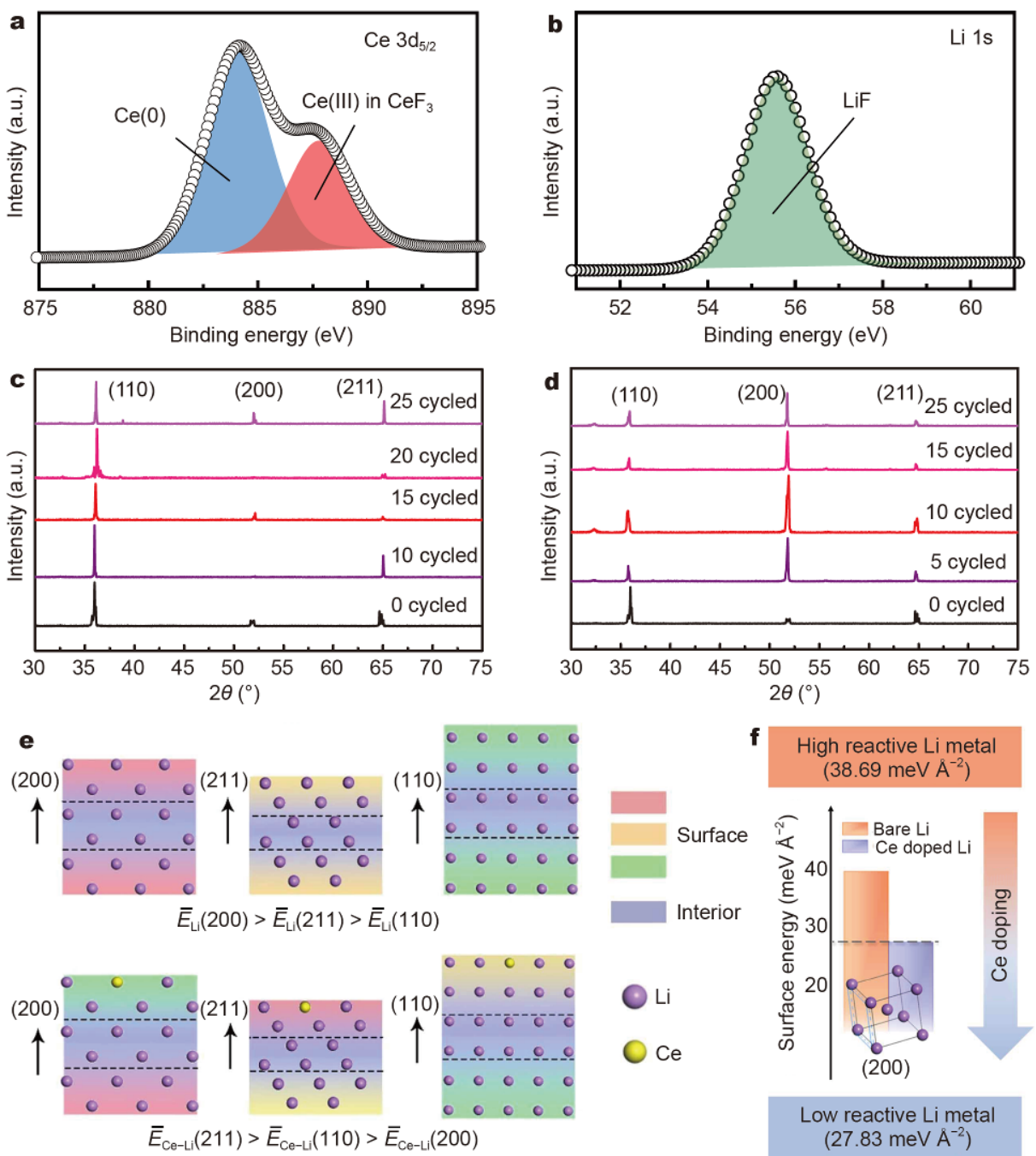

Low reactive Li metal $\left(27.83 \mathrm{meV}^{-2}\right)$

Figure 2 XPS spectra of Ce $3 \mathrm{~d}_{5 / 2}$ (a) and Li 1s (b) of the Ce-doped Li metal before cycling. XRD patterns of bare Li metal (c) and the Ce-doped Li metal (d) after different numbers of cycles. (e) Slab structures of Li with and without Ce doping, atomic positions and lattice constants in fully relaxed configurations. (f) Schematic diagram for surface energy change for (200) planes of Li with/without Ce doping.

$\mathrm{CE}$ (Fig. S6). The $\mathrm{CeF}_{3}$-modified $\mathrm{Cu}$ exhibited an ultrahigh CE over the lifespan, as high as $99.04 \%$ on average over 150 cycles, confirming that the Ce-doped Li metal leads to diminished side reactions with the electrolyte.

Ex-situ SEM was performed to evaluate the morphologies of Li metal anodes after cycling. After 100 cycles, the bare Li metal exhibits a very rough and moss-like morphology (Fig. 4a, c). Moreover, a PVDF-coated (no $\mathrm{CeF}_{3}$ ) Li metal shows only marginal improvement (Fig. S7a, b). As reported previously, the presence of LiF and PVDF in an artificial SEI can improve the stability of the protected Li metal, with an improved morphology and expected improved electrochemical performance $[61,62]$. In our case, the $\mathrm{LiF}$ is generated $i n$-situ, ensuring an intimate contact with the Li metal, and the LiF-coated $\mathrm{Li}$ metal shows an improved morphology after cycling; however, there still exist cracks and signally increased thickness of the SEI (Fig. S8a, b), which means that just the in-situ generated LiF that contacts with Li metal intimately shows insufficient passivating effect to improve the interfacial stability. With the in-situ Ce-doped $\mathrm{Li}$ metal, a smooth and dense morphology is found after cycling (Fig. 4b, d), further pointing to the important role of Ce doping in the stabilization of Li metal. All above results suggest that the stability of Li towards electrolyte components is remarkably improved by insitu Ce doping, by which the consumption of electrolyte and the accumulation of cracked Li fragments are ef- 

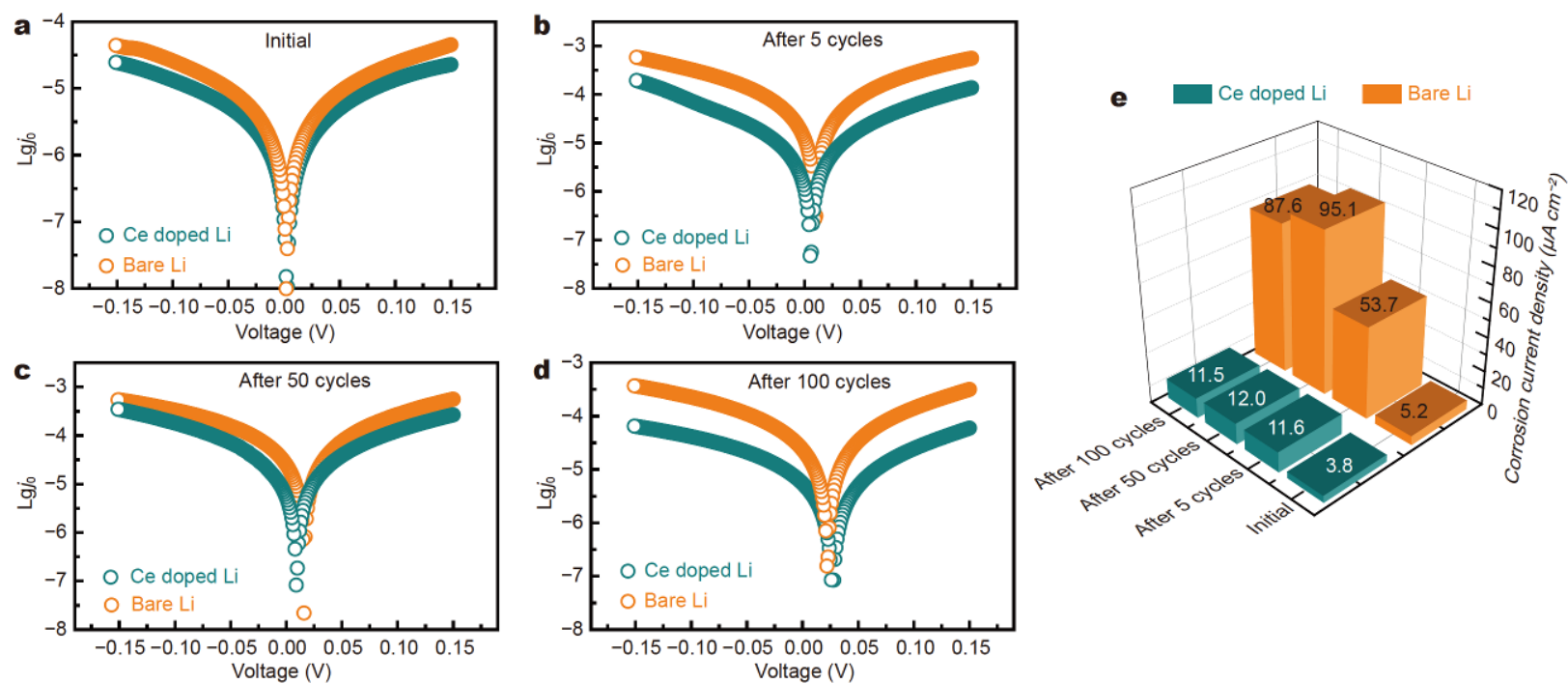

Figure 3 Potentiodynamic polarization curves of the Ce-doped Li metal and bare Li metal (a) before cycling, and after (b) 5 , (c) 50 and (d) 100 cycles. Comparison of corrosion current density of bare Li metal and Ce-doped Li metal as a function of cycling (e).

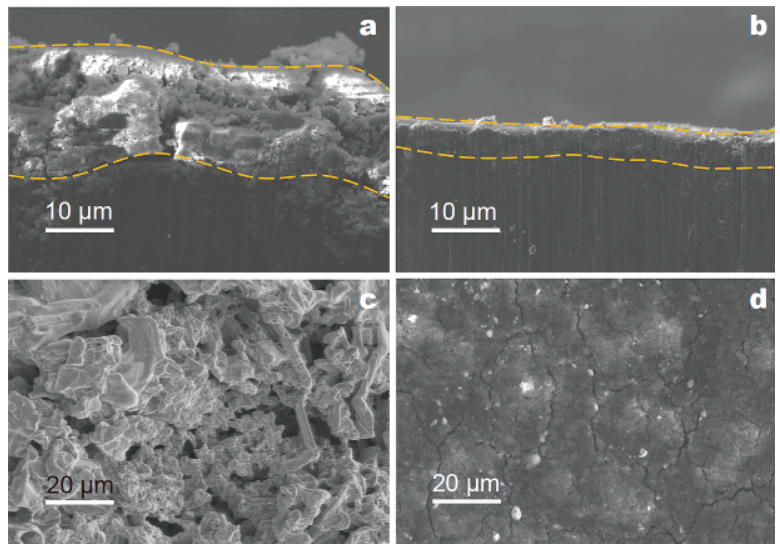

Figure 4 Cross-sectional (a) and top-view (c) SEM images of Li metal after 100 cycles without Ce doping. Cross-sectional (b) and top-view (d) SEM images of the Ce-doped Li metal after 100 cycles.

fectively suppressed.

To confirm the improved electrochemical performance of the Ce-doped Li metal, galvanostatic cycling tests were conducted on the symmetric cells with different amounts of electrolyte. At a sufficient electrolyte condition $(23 \mu \mathrm{L}$ electrolyte per $1 \mathrm{~mA} \mathrm{~h} \mathrm{Li} \mathrm{metal),} \mathrm{the} \mathrm{cell} \mathrm{with} \mathrm{Ce-doped}$ Li metal shows no increase of the cell overpotential over $1000 \mathrm{~h}$ at a current density of $1.0 \mathrm{~mA} \mathrm{~cm}^{-2}$ (Fig. 5a) and negligible increase over $500 \mathrm{~h}$ at a current density of $2.0 \mathrm{~mA} \mathrm{~cm}^{-2}$ (Fig. S9), much better than that of Li anodes without doping (Fig. S10 for PVDF-coated Li metal, and Fig. S3 for LiF-coated Li metal). A high reactivity of $\mathrm{Li}$ metal will accelerate the failure of battery, particularly under the lean electrolyte condition, which is crucial to achieve a high energy-density in practical applications. The rapid fading of the cells with bare Li metal is mainly attributed to the consumption of electrolyte under lean electrolyte condition and the loss of active $\mathrm{Li}$ under sufficient electrolyte condition $[63,64]$. In order to demonstrate the suppressed consumption of electrolyte by $\mathrm{Ce}$ doping, symmetric cells with lean electrolyte condition $(8.6 \mu \mathrm{L}$ electrolyte per $1 \mathrm{~mA} \mathrm{~h} \mathrm{Li} \mathrm{metal)} \mathrm{were} \mathrm{tested.} \mathrm{For}$ the cell with bare Li metal, the polarization increases markedly after only $50 \mathrm{~h}$ of cycling, which is most likely due to the degradation and running out of electrolyte, whereas the cell with the Ce-doped Li metal shows negligible change over $300 \mathrm{~h}$ of cycling (Fig. 5b). Moreover, there is a retention of electrolyte and no black "dead Li" is found after cycling with Ce-doped Li metal (Fig. S11). To the best of our knowledge, the performance shown here is the best ever reported at such low electrolyte/Li ratio and high current density.

To demonstrate the applicability of the Ce-doped $\mathrm{Li}$ metal electrode in practical applications, full $\mathrm{Li} \mid \mathrm{LiCoO}_{2}$ cells were assembled and tested at rates of 2 and $5 \mathrm{C}$, respectively. The cell with Ce-doped $\mathrm{Li}$ metal delivers an initial specific capacity of $133 \mathrm{~mA} \mathrm{~h} \mathrm{~g}^{-1}$ and retains a capacity of $95 \mathrm{~mA} \mathrm{~h} \mathrm{~g}^{-1}$ after 300 cycles at $2 \mathrm{C}(1 \mathrm{C}=$ $140 \mathrm{~mA} \mathrm{~h} \mathrm{~g}^{-1}$, Fig. $5 \mathrm{c}$ and e). Even at the relatively high rate of $5 \mathrm{C}, 75 \%$ of the initial discharge capacity is retained after 300 cycles (Fig. S12). In contrast, the cells with bare $\mathrm{Li}$ metal show a rapid capacity fade to $25 \mathrm{~mA} \mathrm{~h} \mathrm{~g}^{-1}$ after 350 cycles (Fig. 5c) at $2 \mathrm{C}$ and 

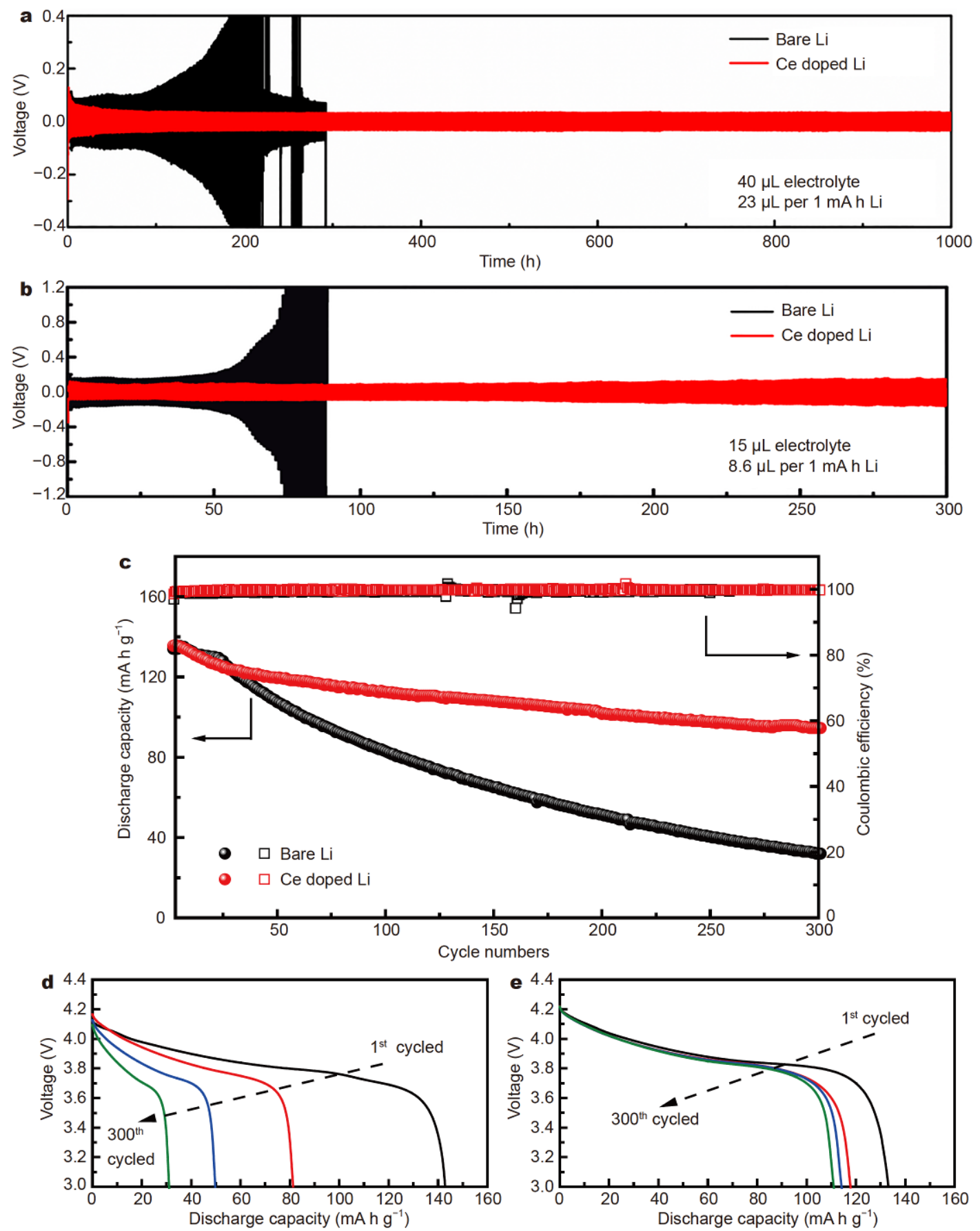

Figure 5 Voltage profiles of $\mathrm{Li}$ metal electrodes tested in symmetric cells at $1.0 \mathrm{~mA} \mathrm{~cm}^{-2}$ with (a) sufficient electrolyte and (b) lean electrolyte conditions. Cycling performance of $\mathrm{Li} \mid \mathrm{LiCoO}_{2}$ full cells with bare Li metal and Ce-doped Li metal electrodes at rate of $2 \mathrm{C}$ (c). Discharge profiles of $\mathrm{Li} \mid \mathrm{LiCoO}_{2}$ full cells with (d) bare $\mathrm{Li}$ and (e) Ce-doped Li metal anodes.

$62 \mathrm{~mA} \mathrm{~h} \mathrm{~g}^{-1}$ after only 100 cycles at $5 \mathrm{C}$. The long cycle life of the full cells with Ce-doped Li metal, particularly under lean electrolyte conditions, further confirms that the suppression of side reactions on Li metal.

\section{CONCLUSIONS}

We report on an innovative approach to achieve highly stable Li metal electrodes through surface energy adjustment via Ce doping. The Ce doping is accomplished in- 
situ on Li surface through the reduction of $\mathrm{CeF}_{3}$ coating. We find that Ce doping can transform the preferred growth orientation of Li metal, from (110) to (200), during the electrochemical plating-striping process. This change leads to a lower surface energy and significantly suppressed side reactions between $\mathrm{Li}$ and the liquid electrolyte. As a result, the Ce-doped Li metal exhibits smooth and dense morphology with cycling. The improved stability is realized over $1000 \mathrm{~h}$ cycling in symmetric cell at a current density of $1.0 \mathrm{~mA} \mathrm{~cm}^{-2}$ and a remarkable capacity retention is shown in $\mathrm{Li} \mid \mathrm{LiCoO}_{2}$ full cells. The tuning of the surface energy of metallic Li with Ce doping shows a route to low reactive Li metal electrodes for advanced rechargeable Li metal batteries.

\section{Received 24 December 2019; accepted 24 February 2020;} published online 20 March 2020

1 Li H. Practical evaluation of Li-ion batteries. Joule, 2019, 3: 911914

2 Zeng X, Li M, Abd El-Hady D, et al. Commercialization of lithium battery technologies for electric vehicles. Adv Energy Mater, 2019, 9: 1900161

3 Nitta N, Wu F, Lee JT, et al. Li-ion battery materials: Present and future. Mater Today, 2015, 18: 252-264

4 Bruce PG, Freunberger SA, Hardwick LJ, et al. Li-O ${ }_{2}$ and Li-S batteries with high energy storage. Nat Mater, 2011, 11: 19-29

5 Liu J, Bao Z, Cui Y, et al. Pathways for practical high-energy longcycling lithium metal batteries. Nat Energy, 2019, 4: 180-186

6 Liu B, Zhang JG, Xu W. Advancing lithium metal batteries. Joule, 2018, 2: 833-845

7 Lu D, Shao Y, Lozano T, et al. Failure mechanism for fast-charged lithium metal batteries with liquid electrolytes. Adv Energy Mater, 2015, 5: 1400993

8 Zhang SS. Problem, status, and possible solutions for lithium metal anode of rechargeable batteries. ACS Appl Energy Mater, 2018, 1: 910-920

9 Schmitz R, Ansgar Müller R, Wilhelm Schmitz R, et al. SEI investigations on copper electrodes after lithium plating with Raman spectroscopy and mass spectrometry. J Power Sources, 2013, 233: 110-114

10 Xiong S, Regula M, Wang D, et al. Toward better lithium-sulfur batteries: Functional non-aqueous liquid electrolytes. Electrochem Energ Rev, 2018, 1: 388-402

11 Zhang SJ, Gao ZG, Wang WW, et al. A natural biopolymer film as a robust protective layer to effectively stabilize lithium-metal anodes. Small, 2018, 14: 1801054

12 Li G, Gao Y, He X, et al. Organosulfide-plasticized solid-electrolyte interphase layer enables stable lithium metal anodes for long-cycle lithium-sulfur batteries. Nat Commun, 2017, 8: 850

13 Gao Y, Zhao Y, Li YC, et al. Interfacial chemistry regulation via a skin-grafting strategy enables high-performance lithium-metal batteries. J Am Chem Soc, 2017, 139: 15288-15291

14 Yan C, Cheng XB, Tian Y, et al. Dual-layered film protected lithium metal anode to enable dendrite-free lithium deposition. Adv Mater, 2018, 30: 1707629

15 Wood KN, Noked M, Dasgupta NP. Lithium metal anodes: toward an improved understanding of coupled morphological, electrochemical, and mechanical behavior. ACS Energy Lett, 2017, 2: 664672

16 Cheng XB, Zhang R, Zhao CZ, et al. A review of solid electrolyte interphases on lithium metal anode. Adv Sci, 2016, 3: 1500213

17 Lin D, Liu Y, Cui Y. Reviving the lithium metal anode for highenergy batteries. Nat Nanotech, 2017, 12: 194-206

18 Cheng XB, Zhang R, Zhao CZ, et al. Toward safe lithium metal anode in rechargeable batteries: a review. Chem Rev, 2017, 117: 10403-10473

19 Zhang H, Eshetu GG, Judez X, et al. Electrolyte additives for lithium metal anodes and rechargeable lithium metal batteries: Progress and perspectives. Angew Chem Int Ed, 2018, 57: 15002 15027

20 Xiong S, Scheers J, Aguilera L, et al. Role of organic solvent addition to ionic liquid electrolytes for lithium-sulphur batteries. RSC Adv, 2015, 5: 2122-2128

21 Weber R, Genovese M, Louli AJ, et al. Long cycle life and dendritefree lithium morphology in anode-free lithium pouch cells enabled by a dual-salt liquid electrolyte. Nat Energy, 2019, 4: 683-689

22 Basile A, Bhatt AI, O'Mullane AP. Stabilizing lithium metal using ionic liquids for long-lived batteries. Nat Commun, 2016, 7: ncomms 11794

23 Liang J, Li X, Zhao $\mathrm{Y}$, et al. In situ $\mathrm{Li}_{3} \mathrm{PS}_{4}$ solid-state electrolyte protection layers for superior long-life and high-rate lithium-metal anodes. Adv Mater, 2018, 30: 1804684

24 Zheng J, Engelhard MH, Mei D, et al. Electrolyte additive enabled fast charging and stable cycling lithium metal batteries. Nat Energy, 2017, 2: 17012

25 Qian J, Henderson WA, Xu W, et al. High rate and stable cycling of lithium metal anode. Nat Commun, 2015, 6: 6362

26 Xiao L, Zeng Z, Liu X, et al. Stable Li metal anode with "ionsolvent-coordinated" nonflammable electrolyte for safe Li metal batteries. ACS Energy Lett, 2019, 4: 483-488

27 Zheng J, Chen S, Zhao W, et al. Extremely stable sodium metal batteries enabled by localized high-concentration electrolytes. ACS Energy Lett, 2018, 3: 315-321

28 Fan X, Chen L, Ji X, et al. Highly fluorinated interphases enable high-voltage Li-metal batteries. Chem, 2018, 4: 174-185

29 Zhang XQ, Chen X, Cheng XB, et al. Highly stable lithium metal batteries enabled by regulating the solvation of lithium ions in nonaqueous electrolytes. Angew Chem, 2018, 130: 5399-5403

30 Li S, Dai $\mathrm{H}, \mathrm{Li} \mathrm{Y}$, et al. Designing Li-protective layer via $\mathrm{SOCl}_{2}$ additive for stabilizing lithium-sulfur battery. Energy Storage Mater, 2019, 18: 222-228

31 Yoo DJ, Elabd A, Choi S, et al. Highly elastic polyrotaxane binders for mechanically stable lithium hosts in lithium-metal batteries. Adv Mater, 2019, 31: 1901645

32 Huang Z, Zhou G, Lv W, et al. Seeding lithium seeds towards uniform lithium deposition for stable lithium metal anodes. Nano Energy, 2019, 61: 47-53

33 Xie J, Liao L, Gong Y, et al. Stitching h-BN by atomic layer deposition of $\mathrm{LiF}$ as a stable interface for lithium metal anode. Sci Adv, 2017, 3: eaao3170

34 Zhao Y, Li G, Gao Y, et al. Stable Li metal anode by a hybrid lithium polysulfidophosphate/polymer cross-linking film. ACS Energy Lett, 2019, 4: 1271-1278

35 Cheng XB, Yan $\mathrm{C}$, Chen X, et al. Implantable solid electrolyte interphase in lithium-metal batteries. Chem, 2017, 2: 258-270

36 Xu R, Xiao Y, Zhang R, et al. Dual-phase single-ion pathway in- 
terfaces for robust lithium metal in working batteries. Adv Mater, 2019, 31: 1808392

37 Gao Y, Yan Z, Gray JL, et al. Polymer-inorganic solid-electrolyte interphase for stable lithium metal batteries under lean electrolyte conditions. Nat Mater, 2019, 18: 384-389

38 Kim MS, Ryu JH, Deepika JH, et al. Langmuir-Blodgett artificial solid-electrolyte interphases for practical lithium metal batteries. Nat Energy, 2018, 3: 889-898

39 Zinigrad E, Levi E, Teller $\mathrm{H}$, et al. Investigation of lithium electrodeposits formed in practical rechargeable $\mathrm{Li}-\mathrm{Li}_{x} \mathrm{MnO}_{2}$ batteries based on $\mathrm{LiAsF}_{6} / 1,3$-dioxolane solutions. J Electrochem Soc, 2004, 151: A111

40 Li Y, Huang W, Li Y, et al. Correlating structure and function of battery interphases at atomic resolution using cryoelectron microscopy. Joule, 2018, 2: 2167-2177

41 Li Y, Li Y, Pei A, et al. Atomic structure of sensitive battery materials and interfaces revealed by cryo-electron microscopy. Science, 2017, 358: 506-510

42 Shi F, Pei A, Vailionis A, et al. Strong texturing of lithium metal in batteries. Proc Natl Acad Sci USA, 2017, 114: 12138-12143

43 Jäckle M, Helmbrecht K, Smits M, et al. Self-diffusion barriers: Possible descriptors for dendrite growth in batteries? Energy Environ Sci, 2018, 11: 3400-3407

44 Pei A, Zheng G, Shi F, et al. Nanoscale nucleation and growth of electrodeposited lithium metal. Nano Lett, 2017, 17: 1132-1139

45 Akolkar R. Mathematical model of the dendritic growth during lithium electrodeposition. J Power Sources, 2013, 232: 23-28

46 Kushima A, So KP, Su C, et al. Liquid cell transmission electron microscopy observation of lithium metal growth and dissolution: Root growth, dead lithium and lithium flotsams. Nano Energy, 2017, 32: 271-279

47 Jin Y, Zhou L, Yu J, et al. In operando plasmonic monitoring of electrochemical evolution of lithium metal. Proc Natl Acad Sci USA, 2018, 115: 11168-11173

48 Aleiner IL, Larkin AI. Divergence of classical trajectories and weak localization. Phys Rev B, 1996, 54: 14423-14444

49 Perdew JP, Burke K, Ernzerhof M. Generalized gradient approximation made simple. Phys Rev Lett, 1996, 77: 3865-3868

50 Barreca D, Gasparotto A, Maccato C, et al. Cerium (III) fluoride thin films by XPS. Surf Sci Spectra, 2006, 13: 87-93

51 Ong SP, Richards WD, Jain A, et al. Python Materials Genomics (pymatgen): A robust, open-source python library for materials analysis. Comput Mater Sci, 2013, 68: 314-319

52 Valencia H, Kohyama M, Tanaka S, et al. First-principles study of EMIM-FAFSA molecule adsorption on a $\mathrm{Li}(100)$ surface as a model for Li-ion battery electrodes. J Phys Chem C, 2012, 116: 8493-8509

53 Lei Z, Zhang Q, Zhu X, et al. Corrosion performance of $\mathrm{ZrN} / \mathrm{ZrO}_{2}$ multilayer coatings deposited on 304 stainless steel using multi-arc ion plating. Appl Surf Sci, 2018, 431: 170-176

54 Pandey V, Singh JK, Chattopadhyay K, et al. Optimization of USSP duration for enhanced corrosion resistance of AA7075. Ultrasonics, 2019, 91: 180-192

55 Wei YK, Li YJ, Zhang Y, et al. Corrosion resistant nickel coating with strong adhesion on AZ31B magnesium alloy prepared by an in-situ shot-peening-assisted cold spray. Corrosion Sci, 2018, 138: 105-115

56 Zhang XQ, Chen X, Xu R, et al. Columnar lithium metal anodes. Angew Chem Int Ed, 2017, 56: 14207-14211

57 Yu HL, Zhao JN, Ben LB, et al. Dendrite-free lithium deposition with self-aligned columnar structure in a carbonate-ether mixed electrolyte. ACS Energy Lett, 2017, 2: 1296-1302

58 Zhang Y, Qian J, Xu W, et al. Dendrite-free lithium deposition with self-aligned nanorod structure. Nano Lett, 2014, 14: 68896896

59 Choudhury S, Archer LA. Lithium fluoride additives for stable cycling of lithium batteries at high current densities. Adv Electron Mater, 2016, 2: 1500246

60 Zhang XQ, Cheng XB, Chen X, et al. Fluoroethylene carbonate additives to render uniform Li deposits in lithium metal batteries. Adv Funct Mater, 2017, 27: 1605989

61 Luo J, Fang CC, Wu NL. High polarity poly(vinylidene difluoride) thin coating for dendrite-free and high-performance lithium metal anodes. Adv Energy Mater, 2018, 8: 1701482

$62 \mathrm{Xu} \mathrm{R}$, Zhang XQ, Cheng XB, et al. Artificial soft-rigid protective layer for dendrite-free lithium metal anode. Adv Funct Mater, 2018, 28: 1705838

63 Long BR, Rinaldo SG, Gallagher KG, et al. Enabling high-energy, high-voltage lithium-ion cells: Standardization of coin-cell assembly, electrochemical testing, and evaluation of full cells. J Electrochem Soc, 2016, 163: A2999-A3009

64 Nagpure SC, Tanim TR, Dufek EJ, et al. Impacts of lean electrolyte on cycle life for rechargeable Li metal batteries. J Power Sources, 2018, 407: 53-62

Acknowledgements This work was supported by the National Natural Science Foundation of China (51602250, 51802256 and 21875181), and the Innovation Capability Support Program of Shaanxi (2018PT-28 and 2019PT-05).

Author contributions Liu Y and Xiong S conceived the study, performed the experiments and wrote the manuscript. Deng J performed the computational section. Song B assisted with morphology characterization of $\mathrm{Li}$ samples. Jiao $\mathrm{X}$ and Matic A were involved in the discussion and writing of the manuscript. Song J directed the project and organized the discussion as well as preparation of the manuscript.

Conflict of interest The authors declare that they have no conflict of interest.

Supplementary information Supporting data are available in the online version of the paper. 


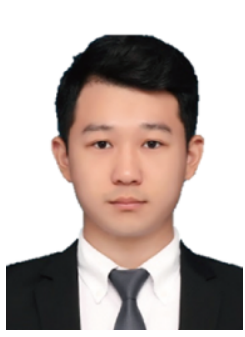

Yangyang Liu is currently a $\mathrm{PhD}$ candidate under the supervision of Professor Jiangxuan Song and Professor Zhongxiao Song at Xi'an Jiaotong University. His research interests mainly focus on the solid electrolyte, interface engineering and stabilization of lithium metal for high-energydensity rechargeable lithium metal batteries.

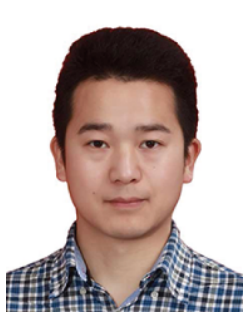

Shizhao Xiong is currently a post-doctoral researcher in the Department of Physics at Chalmers University of Technology. He received a PhD degree in materials science and engineering from the National University of Defense Technology in 2015. His research interests are mainly focused on the characterization and modification of interface for advanced energy storage system, including lithium sulfur batteries, ionic liquid electrolyte, lithium metal anode and solid-state lithium batteries.

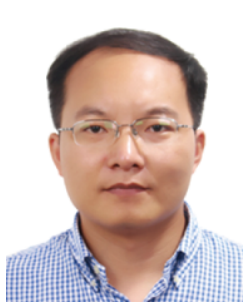

Jiangxuan Song is currently a professor in the School of Materials Science and Engineering at Xi'an Jiaotong University. He received his $\mathrm{PhD}$ degree from Beijing University of Chemical Technology in 2010. Dr. Song's main research interests are in the fields of novel energy storage and conversion systems, including lithium-sulfur batteries, sodium-ion batteries, lithium metal anode and polymer binders.
通过原位表面掺杂实现稳定金属锂负极的晶体定 向沉积

刘洋洋 ${ }^{1 \dagger}$, 熊仕昭 ${ }^{2 \dagger}$, 邓俊楷, 焦星星 ${ }^{1}$, 宋宝点 ${ }^{1}$, Aleksandar Matic ${ }^{2}$, 宋江选 $^{1 *}$

摘要 锂金属由于其高理论比容量 $\left(3860 \mathrm{~mA} \mathrm{~g}^{-1}\right)$ 而被认为是最具 潜力的高能量密度锂电池用负极材料. 然而, 锂枝晶的不可控生长 和金属锂对电解液的高反应活性严重阻碍了其实际应用. 区别于 以往广泛使用的电解液优化或界面修饰工艺, 本文采用一种原位 铈掺杂的策略, 从根本上改变了锂金属的电沉积行为. 通过锂电极 表面的原位铈掺杂促进锂在电化学过程中沿 [200]方向优先沉积, 显著降低金属锂的表面能. 光谱、形貌和电化学测试等结果证明, 原位铈掺杂大大降低了锂电极对电解液的反应活性, 使得电极在 沉积/脱出过程中具有无枝晶形貌. 采用这种策略装配的对称电池 中, 锂电极具有低腐蚀电流密度, 甚至在贫液条件下循环寿命也得 到显著提升. 采用铈掺杂锂负极的锂-钴酸锂全电池可稳定循环 300 周，库伦效率和循环寿命得到明显提高. 本工作为金属锂负极在高 能量密度电池中的实用化研究提供了一种具有启发性的策略. 